\title{
Thermal biology in insect-parasite interactions
}

\author{
Matthew B. Thomas ${ }^{1}$ and Simon Blanford ${ }^{2}$ \\ ${ }^{1}$ Department of Agricultural Sciences, Imperial College London, Wye Campus, Wye, Ashford, Kent TN25 5AH, UK \\ ${ }^{2}$ University of Edinburgh, Ashworth Laboratories, King's Buildings, West Mains Road, Edinburgh EH9 3JT, UK
}

\begin{abstract}
Recently, several applied studies exploring the use of pathogens for insect biocontrol have demonstrated significant effects of environmental temperature on the outcome of infection. For example, host resistance, host recovery, pathogen virulence and replication can alter considerably with sometimes very small changes in temperature. Moreover, the effectiveness of certain insect parasitoids and the activity of endosymbionts can vary across the range of realistic temperatures experienced in the field. These responses are not necessarily linear or immediately predictable, because they derive from a complex 'genotype-by-genotype-byenvironment' interaction. Given the importance of parameters such as virulence and resistance in determining the course of a host-parasite interaction, such effects of temperature could have profound implications for host-parasite dynamics and coevolution.
\end{abstract}

That temperature affects biochemical, physiological and behavioural processes in animals is well established and there has been much work exploring the thermal sensitivity of organisms and factors influencing the evolution of thermal performance curves (Box 1). Ecological and evolutionary studies of interactions between hosts and their pathogens and parasites have a similar pedigree. What has been somewhat neglected is the integration of these two research areas to consider the effects that temperature can have on interactions between organisms [i.e. genotype-by-genotype-by-environment, or $\mathrm{G} \times \mathrm{G} \times \mathrm{E}$, INTERACTIONS (see Glossary)]. To some extent, this might have arisen out of a tendency to abstract systems down to their basic biotic components to make research problems more tractable. However, there is an increasing number of examples, many from more applied disciplines, such as biological pest control, which point to environmental temperature having a crucial role in mediating the outcome of host-parasite interactions (for the sake of brevity, we refer simply to host-parasite interactions to include pathogens, macroparasites and parasitoids). Our aim here is to highlight some of these examples, examine the mechanisms involved and then explore some of the implications for our fundamental understanding of the ecology and evolution of host-parasite interactions. In drawing on the biocontrol literature and examples from other common 'model' systems, we emphasize studies of insect or other invertebrate hosts. However, many of these issues apply to a range of ECTOTHERMS and their natural parasites.

\section{Effects of temperature on host-pathogen/parasite interactions}

Driven by the desire to develop alternatives to chemical insecticides, there have been many studies exploring the potential of pathogens and parasites for use in biological pest control [1]. A common starting point for most of this work is the investigation of dose responses and host mortality rates under constant laboratory conditions. The resulting measures of $\mathrm{LD}_{50}$ and $\mathrm{LT}_{50}$ are then used to select the most promising (virulent) agents for further testing in the field. This approach is also typical of many of the more

\section{Glossary}

Acridid: family of grasshoppers with short antennae. The acridids include the locusts that are a select group of grasshoppers able to pass into a swarming phase subject to the right environmental conditions.

Behavioural thermoregulation: the use of behaviour, such as avoiding or seeking sources of heat, to regulate body temperature.

Cellular and humoral defense mechanisms: refers to the two components of the insect immune system. The humoral response consists of soluble factors in the blood such as antimicrobial peptides and phenoloxidases. The cellular component involves the activity of specialized cells collectively called haemocytes. Haemocytes secrete antimicrobial peptides and are involved phagocytosis of small foreign objects and encapsulation of large objects. Ectotherm: an animal that derives much of its body heat from external heat sources.

Encapsulation: an immune response in which large foreign bodies, such as eggs of parasitoids, are surrounded and suffocated by blood haemocytes.

Entomophthoralean (fungi): an order of entomopathogenic fungi that have complex life cycles involving a sexual stage and resting spores.

Frequency dependent selection: An evolutionary process where the fitness of a genotype is dependent on the relative frequency of other genotypes in the population. In a host-parasite context, we would expect initially rare resistant hosts to become more common under the pressure of parasite selection.

$\mathbf{G} \times \mathbf{G} \times \mathbf{E}$ interaction: The phenotype of an individual plant or animal is a consequence of the interaction between its genotype $(G)$ and the environment $(E)$ in which it exists i.e. a ' $G \times E^{\prime}$ ' interaction. In considering the role of environment on a host and its parasite we extend the concept to include both interacting genotypes i.e. $\mathrm{G} \times \mathrm{G} \times \mathrm{E}$.

$\mathbf{L T}_{\mathbf{5 0}}$ : The median lethal time is the time required to produce death in $50 \%$ of the infected individuals exposed to a specific dosage of pathogens.

$\mathbf{L D}_{50}$ : The median lethal concentration or dose of a pathogen that produces death in $50 \%$ of the treated subjects. Usually a time period is stated, e.g. number of days post inoculation.

Mitosporic fungi: a group of fungi with a simple life cycle with no known sexual stage.

Reaction norm: describes the phenotypic variation among individuals of a single genotype when it is exposed to different environments.

Thermoconformer: an organism that does not attempt to regulate body temperatures but allows its body temperature to closely track environmental temperatures. 


\section{Box 1. Thermal sensitivity profiles}

The thermal sensitivity of ectotherm performance has been extensively studied and representation of ectotherm performance across temperature is traditionally summarized as a nonlinear asymmetric curve [70-72] (Fig. la). Optimal temperature $\left(T_{0}\right)$ is defined as the temperature at which the trait measured (e.g. sprint speed in reptiles [73], or pathogen growth [39]) occurs at its maximal rate. $C T_{\min }$ and $C T_{\max }$ are the critical thermal minimum and maximum of thermally dependent performance (although not necessarily the lethal temperatures), respectively. Operative range is the difference between $C T_{\min }$ and $C T_{\max }$ across which some level of performance can be measured. Such curves have been used to explore hypothetical changes in trait performance owing to selection pressure from, for example, a warming environment $[70,74]$.

In considering the interaction between a host and parasite, each organism or genotype will have its own thermal performance curve. These might superimpose directly on one another such that no relative effects of temperature would be expected. Alternatively, as exemplified by locust-fungal systems (and probably several other systems), host and parasite performance curves can show some form of separation (Fig. Ib) [39]. In this case, the course of infection could be strongly influenced by temperature and, particularly, by how temperature varies across the respective operative ranges of host and parasite. In Fig. Ib, high temperatures favour the host by both optimizing defence responses and directly limiting pathogen growth. As a result, there might be little pathogen-induced mortality $[2,39]$. At lower temperatures, pathogen growth might be optimized and host defence is less effective, with the result that the same pathogen appears highly virulent $[2,39]$.

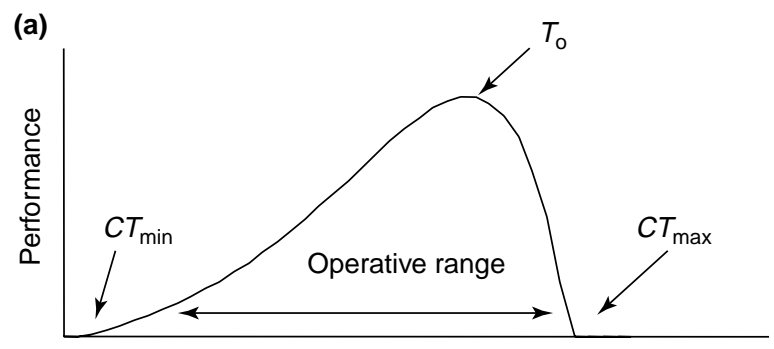

Temperature $\left({ }^{\circ} \mathrm{C}\right)$

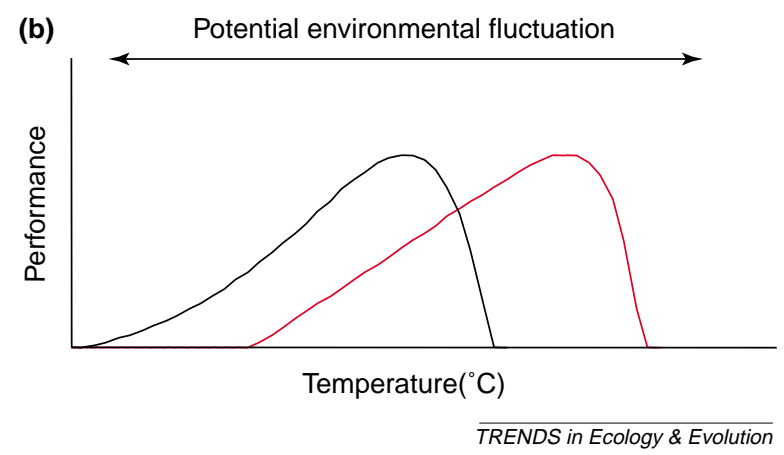

Fig. I. Variation in ectotherm performance (e.g. immune response, growth or feeding rate) across temperature. (a) A typical asymmetrical thermal performance profile indicating upper $\left(C T_{\max }\right)$ and lower critical temperatures $\left(C T_{\min }\right)$ and the temperature at which performance is maximum $\left(T_{\mathrm{o}}\right)$. (b) Performance curves of host and parasite can show some degree of separation. Here, host performance (red) is optimized at a higher temperature than that of the parasite (black).

fundamental studies exploring, for example, variation in resistance and virulence among natural populations. However, an additional common feature of this research is that, when the agents are taken to the field, performance tends to be highly erratic [2,3]. Although there are many factors that can contribute to this variability, recent work on the use of fungal pathogens for biocontrol of locusts and grasshoppers has shown that, in particular, the ability of a pathogen to kill the host depends crucially on host body temperature and how this fluctuates with external environmental conditions. For example, both the speed of kill and overall mortality caused by MITOSPORIC FUNGI, such as Beauveria bassiana and Metarhizium anisopliae var. acridum, vary greatly with changes in environmental temperature [2-7]. Thus, these pathogens might appear either very virulent, causing extensive and rapid mortality of locusts or grasshoppers in 5-10 days, or virtually benign, with the same hosts surviving for weeks or even months.

In the context of biocontrol, it is clearly important for us to understand such temperature-dependent variability because biopesticide products based on these fungi will achieve excellent control under some conditions, whilst they might be largely ineffective and inappropriate for use under other conditions [8]. However, the effects also extend to natural host-pathogen interactions. For example, under certain environmental conditions, the ENTOMOPHTHORALEAN fungal pathogen Entomophaga grylli can act as the key mortality factor in the population dynamics of the variegated grasshopper Zonocerus variegatus [9]. However, during sunny periods, an increase in daytime maximum temperature of just $2^{\circ} \mathrm{C}$ enables infected hosts to recover from disease, creating an effectively immune population [10]. Similar results are revealed from studies of disease dynamics in rangeland grasshoppers in the USA [11].

That relatively small and realistic changes in temperature can dramatically alter apparent levels of susceptibility is not unusual or specific to ACRIDID-fungal systems. For example, strong thermal effects on virulence have been shown for Entomophthora muscae against flies [12], Entomophaga maimaiga against larvae of gypsy moth [13], Erynia radicans against potato leafhopper [14] and Erynia neoaphidis against the pea aphid [15,16], independent of factors acting on transmission and germination. Moreover, thermal effects on host-parasite interactions are not confined to fungal pathogens but include other microbial pathogens, such as rickettsia, microsporidia, bacteria and viruses [17-22], together with nematodes [23].

Temperature can have considerable effects on host susceptibility and/or parasite virulence with parasitoids. For example, there has been extensive research on Drosophila-parasitoid interactions, including studies of the selection of host resistance under high parasitoid pressure and concomitant tradeoffs [24]. But, temperature also plays an important role in determining the relative susceptibility of Drosophila larvae to their different parasitoids. For example, Fellowes et al. investigated cross-resistance against three parasitoid species in Drosophila lines that had been selected for increased defence [25]. Resistance was measured at $15^{\circ} \mathrm{C}, 20^{\circ} \mathrm{C}$ and $25^{\circ} \mathrm{C}$ in unselected and selected lines. Depending on the specific host-parasitoid combination, a range of interactions was possible, with resistance sometimes remaining 


\section{Box 2. Effects of temperature on the outcome of a host-parasite interaction}

The influence of temperature on the outcome of a host-parasite interaction will depend on how temperature affects the ability of the parasite to colonize a host, versus the effect of temperature on the ability of the host to defend itself. If we define virulence as the net effect of this dynamic interaction (i.e. virulence is not necessarily a constant, nor simply an inherent property of the parasite alone) then this provides us with a metric to represent some of the varied effects of temperature highlighted in the main text (although it will not necessarily capture effects, such as changes in pathogen reproductive rate or expression of latent infections, which are also reported).

If both host and parasite are insensitive to temperature or share the same response over a given temperature range, the resulting virulence reaction norm will be flat (Fig. la). However, such insensitivity to temperature might be true only of very few systems, or be representative of a limited temperature range. More typical is some kind of positive or negative response, which can be linear (Fig. Ib) or more complex (Fig. Ic,d). Linear reaction norms appear to result where the range of temperature is still small relative to the

(a)

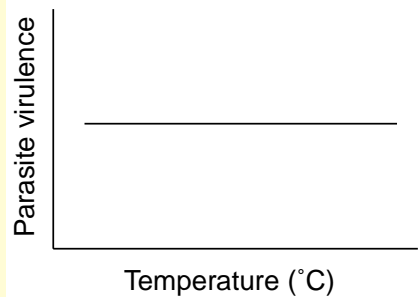

Temperature $\left({ }^{\circ} \mathrm{C}\right)$ (b)

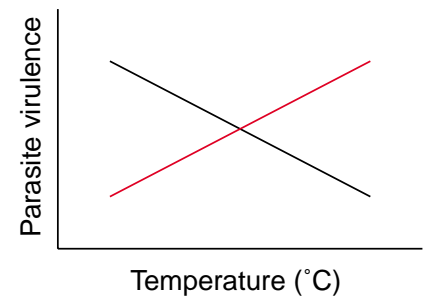

operative ranges of host and/or parasite [25,75]. Exploring effects of temperature across a wider range that encompasses a greater proportion of the thermal performance profiles, and even exceeds the operative ranges, generally reveals more complex nonlinear responses. For example, with insect viruses (Fig. Ic), virulence is generally low at cool temperatures, increases with elevations in temperature and reaches an asymptote as temperature rises further $[17,76]$. Short-term exposures to yet higher temperatures, however, can enable host recovery effectively reducing virulence to zero on return to more permissive temperatures [18]; this is illustrated in (Fig. I) by the broken line, which represents a critical upper temperature at which virulence falls to zero. For other parasites, virulence might increase with an initial rise in temperature and then fall off as temperature increases further (Fig. Id). This pattern is reported for a range of systems described in the main text. However, the reverse pattern is also reported in which virulence is lowest at intermediate temperatures and then increases as temperatures either rise or fall (at least over a limited range) [25]. (c)

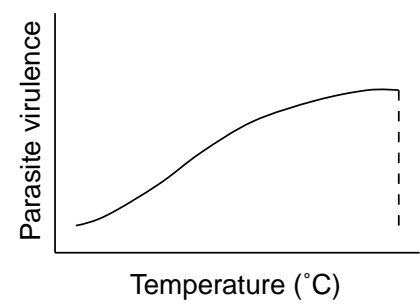

(d)

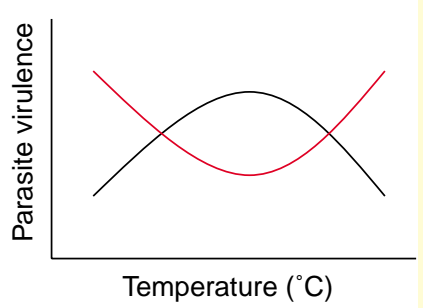

$\overline{\text { TRENDS in Ecology \& Evolution }}$

Fig. I.

more or less constant irrespective of temperature, decreasing linearly with temperature, or following a complex pattern either increasing or decreasing at the extremes. Moreover, Fellowes et al. also showed that a change in thermal regime from $20^{\circ} \mathrm{C}$ to $25^{\circ} \mathrm{C}$ could confer an equivalent level of resistance in an unselected line to that exhibited by the selected line at the base-line temperature. Thermal effects on different aspects of host-parasitoid interactions have also been shown in other systems [26-29], with a fairly common observation that high temperatures can enhance survival of parasitized hosts (although whether this is due to increased ENCAPSULATION of the parasite larvae or pupae by the host, or greater direct mortality of the parasite owing to a higher thermal sensitivity, is often not determined).

There is therefore a range of possible influences of temperature on host-parasite interactions (Box 2) including effects on latent periods of infection [2], expression of latent disease [19], host recovery and parasite mortality $[11,18,21,28]$, parasite replication [18] and parasite virulence and/or host resistance [2,6,23,25-27]. Importantly, and in contrast to the prevailing assumption that temperature acts as a simple scaling factor on rate processes [25], most studies reveal complex nonlinear effects in line with an interaction between host and pathogen thermal sensitivity profiles (Box 1). Evidence for a simple linear effect of temperature on aspects such as susceptibility or mortality rate is quite rare, especially when accounting for the full range of realistic environmental temperatures. Temperature fluctuations and temperature extremes can also result in markedly different effects from those predicted under constant temperatures $[15,16,27]$.

\section{Beyond hosts and their parasites}

The examples we have discussed concern insect hosts and their parasites. However, it is also possible to identify effects of temperature on associations that are not strictly parasitic. For instance, endosymbiotic rickettsia and other bacteria have been isolated from a diversity of host organisms and have a range of effects on host biology [30-32]. Interestingly, although at least some of these endosymbionts are obligate partners, several studies illustrate a difference in thermal sensitivity between these microorganisms and their hosts. For example, relatively short exposure to high temperatures reduces the abundance and even eliminates endosymbionts, such as Wolbachia [33,34] and Buchnera [35], without direct effects on the host (although with obvious indirect effects resulting from loss of the endosymbiont). Moreover, interactions between symbionts are possible whereby one species can reduce the effects of environmental temperature on another [35]. Therefore, the differential effects of temperature on all the 'interacting genomes' should be considered if the ecology of natural insect populations is to be fully understood [35]. This extends also 
Box 3. Influence of thermal behaviour and environment on host body temperature

Most insects (and other ectotherms) adopt one of two thermal strategies: they either regulate body temperature behaviourally, or they conform to the external thermal environment and, within certain extremes, show little thermally mediated behaviour. BEHAVIOURAL THERMOREGULATION (see Box Glossary) enables an organism to achieve optimal body temperature for physiological functions, and is seen most often in insects inhabiting environments that are diurnally or seasonally unpredictable [77-79]. Body temperatures of behavioural thermoregulators tend to vary nonlinearly with ambient temperature [80]. Body temperatures of thermal conformers, however, are expected to track ambient temperatures closely [79]. In practice, thermoregulating insects can exhibit a linear relationship with ambient temperature if there is no source of radiant energy, or the cost of finding suitable thermoregulatory sites is high $[7,81]$. Conversely, THERMOCONFORMERS can exhibit marked nonlinearity in their ambient-body temperature relationship, tending to show an increasing thermal excess as ambient temperature increases [82]. Thus, on a hot day (red line, Fig. I), a behaviourally regulating insect might reach and maintain its preferred body temperature for several hours by balancing heat gain and heat avoidance $[7,83]$ (black line, Fig. I, Day 1$)$. Body temperature of a thermal conformer (blue line, Fig. I) might also reach high levels but for a shorter duration. Under slightly cooler conditions (Fig. I, Day 2), behavioural thermoregulation might again lead to large differences between body temperature and ambient temperature, although the preferred temperature might not be reached. Body temperature of a thermoconforming insect, however, will tend to be much closer to ambient. On a cool day with no radiant source of heat (Fig. I, Day 3), both thermoregulators and thermal conformers will tend to have body temperatures close to

to our understanding of the ecology of vector-borne diseases, for which differential effects of temperature on the parasite and disease vector (together with possible further interactions with endosymbionts [32]) have been identified [36-38].

\section{Mechanisms: parasite growth and host defence}

The effects of temperature on a host-parasite interaction depend on the thermal sensitivity profiles and the environmental variability (Box 1). When both host and parasite share the same thermal optima and are adapted to perform similarly across a temperature range, the effects of temperature can be simple. However, when host and parasite have more discrete thermal performance profiles and temperatures regularly fluctuate across the range of these REACTION NORMS, the nonlinearities in the respective responses of host and parasite can lead to large $\mathrm{G} \times \mathrm{G} \times \mathrm{E}$ effects [15,39].

In many cases, the mechanisms whereby temperature acts on the host-parasite interaction remain poorly understood. In the first instance, the influence of environmental temperature on host body temperature is determined by host thermal behaviour (Box 3). Most locust and grasshoppers, for example, are good thermoregulators and have a suite of behaviours for maintaining a preferred body temperature, which is relatively independent of ambient diurnal temperatures [40]. Given suitable environmental conditions, this thermoregulatory behaviour enables locusts to raise their body temperatures to a preferred set point around $38^{\circ} \mathrm{C}-40^{\circ} \mathrm{C}[2,5,11,40,41]$. Given that the optimum temperature for growth of fungi such as $B$. bassiana and $M$. anisopliae is in the range of $25^{\circ} \mathrm{C}-30^{\circ} \mathrm{C}$, such body temperatures will have a direct

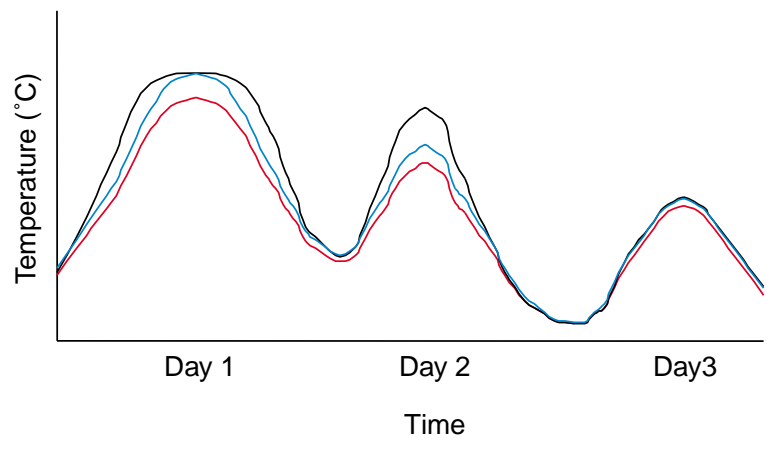

$\overline{T R E N D S ~ i n ~ E c o l o g y ~ \& ~ E v o l u t i o n ~}$

Fig. I.

ambient and will be little different to one another. In addition, irrespective of thermal behaviour in the day, body temperatures of ectotherms will equilibrate with ambient temperatures at night (which will, of course, vary). Moreover, body temperature and behaviour will be affected by the size (and so age and sex), thermal profile, distribution and colour of the insect. Thus, basic measures of ambient temperature, or simplifying assumptions that consider just the mean temperature, will tend not to be representative of the thermal environment in which the host-parasite interaction is actually played out.

effect on pathogen growth, contributing to the substantial delay in the rate of fungus-induced mortality referred to previously $[2,5-7,39]$.

An additional dimension to thermoregulation in locusts and grasshoppers is that certain species exhibit fever responses following infection, whereby thermoregulatory behaviour is modified to enable hosts to attain a new preferred body temperature some $2^{\circ} \mathrm{C}-5^{\circ} \mathrm{C}$ higher than normal $[4,39,41]$. Until very recently, the significance of this 'behavioural fever' response was unclear, because the growth of many pathogens at normal host preferred temperatures of $38^{\circ} \mathrm{C}-40^{\circ} \mathrm{C}$ is already negligible or zero. However, Elliot et al. [39] have now demonstrated that behavioural fever does provide additional survival benefits above and beyond normal thermoregulatory behaviour. That said, it still remains unclear to what extent the survival benefit of fever in Orthoptera and other arthropods results from a direct negative effect of temperature on the pathogen, or from indirect effects via changes in host immune response, or from a combination of both. There is some evidence of a differential fever response depending on the thermal sensitivity of the pathogen, with fever only detected against a pathogen that is negatively affected by higher host temperatures [2,20]. Similarly, fever in honeybee colonies has been suggested as a defense response to Ascosphaera apis (the fungus which causes the disease 'chalk brood'), again through a direct thermal effect on a heat-sensitive pathogen [42]. A recent study of migratory locusts, however, indicated that fever temperatures could play a role in maintaining haemocyte population levels and enhancing host immunity by promoting phagocytosis [43]. Studies of other arthropod taxa report a range of fever responses with temperatures 
elevated by up to $20^{\circ} \mathrm{C}$ and suggest both direct and indirect effects of increased temperature on pathogenesis [44,45]. Moreover, the possibility also exists that parasites can manipulate behaviour (including thermal behaviour) of their hosts to enhance their own virulence and/or fitness $[36,46,47]$. Interestingly, the mechanisms and adaptive significance of fever responses in mammals is also of some debate [46]. Increasingly, analogies and homologies identified between the immune system of insects and innate immunity of higher animals suggest common mechanisms and common effects of temperature and fever across taxa [48-51].

Thermoconforming organisms do not regulate body temperature to the same extent as behavioural regulators at least within the bounds of upper and lower lethal temperatures (Box 3). This might be because the stability of the thermal environment they inhabit $[7,10]$, and/or the size of the insect, preclude tight control of body temperature [26]. As such, body temperature will tend to track ambient temperature more directly and the capacity to utilize temperature actively in defence is minimal (as is the potential for the parasite to manipulate host body temperature for its own fitness). However, lack of thermoregulation does not equate to lack of thermal sensitivity. Thus, environmentally driven variation in body temperature will still influence key elements of the innate immune system, such as CELLULAR AND HUMORAL DEFENSE MECHANISMS [52]. For example, encapsulation of eggs of the parasitoid Metaphycus stanleyi by the pyriform scale Protopulvinaria pyriformis is correlated with ambient temperature creating marked seasonal variation in the effectiveness of the parasitoid [26]. In addition, changes in host body temperature can also impact directly on the parasite. With the entomoptheralean fungi, for instance, exposure to high temperatures can cause cell lysis enabling hosts to recover from infection $[11,15]$. For other pathogens, such as nucleopolyhedroviruses, effects can be more complex, with individual traits (e.g. incubation time and yield) showing different thermal sensitivities within and between hosts $[17,22,53]$.

In summary, the body temperature of ectotherms is dependent on environmental temperature, with the exact relationship determined by several ecological factors, particularly thermal behaviour (Box 3). In turn, host body temperature determines performance of the parasite, either directly, or through effects on host defence mechanisms. In addition, in many systems, biotic factors, such as the host density and extent of melanization, also influence overall resistance levels [54,55]. The interaction between such biotic and abiotic influences has been largely neglected [3] and is only now receiving attention $[56,57]$.

\section{Implications for population dynamics and the evolution of host-parasite interactions}

Although there are very few published studies that examine the consequences of temperature-induced effects on host-parasite population dynamics, measures of host susceptibility, host recovery, latent period of infection, pathogen-induced mortality rate (virulence) and pathogen replication are included in some form in most host- parasite models. As previously discussed, temperature can impact on all of these parameters, either singly or in combination. It follows then that temperature must impact on host-parasite dynamics, either quantitatively or qualitatively, a conclusion that is supported when temperature is modeled explicitly [13]. Of particular relevance is that variation in environmental temperature can be considerable across even very small temporal and spatial scales. In addition, host body temperatures can also vary with biotic factors, such as behaviour, density and body colour $[58,59]$. Such variation might severely limit the generality of model predictions based on parameters estimated under just one set of conditions.

In an evolutionary context, numerous studies have identified genetic variation in defence and virulence in host-parasite associations [60-63]. However, there has been difficulty in demonstrating that laboratory-observed genetic variation can lead to FREQUENCY-DEPENDENT SELECTION in the field $[62,64]$. Given that environmental temperature has the potential to alter virulence and resistance in such systems (demonstrated for the Drosophila and pea aphid systems, which show marked nonlinearities in responses to temperature [15,16,25]), this suggests that variability in environmental temperature could play a role in mediating the pattern of frequency-dependent selection. In other words, with temperature altering virulence and resistance and causing the selection pressure to shift over time and/or space, the net effect of frequency-dependent selection at the population level might be very different from that predicted under one set of conditions in the laboratory $[15,16]$. Although this remains to be tested, it is interesting to note that, under controlled laboratory conditions, genetic variation has been shown to provide the basis for selection of resistant host genotypes [24]. More generally, coevolutionary dynamics have most clearly been demonstrated in endothermic host-parasite associations [65,66]. Both these situations represent environments in which extrinsic variability is removed.

\section{Conclusions and recommendations}

Our key message here is that, in studying host-parasite interactions, environment matters. More specifically, the course of an interaction is determined by host body temperature, which, depending on thermal behaviour, might not be close to ambient. Where some distinction exists between thermal sensitivity profiles of host and parasite, environmental temperature, via its influence on host body temperature, might have complex effects that are not necessarily immediately predictable.

Clearly, understanding such complex interactions poses considerable experimental challenges, even more so when one considers that temperature is unlikely to be the only environmental determinant $[67,68]$. However, there are several basic approaches that could provide relatively rapid insight into the possible importance of environmental temperature on host-parasite interactions. First, in considering whether the influence of temperature is likely to lead to any complex effects, a useful starting point is to determine the temperature-dependent performance curves for each interacting species (or genotype). For many 
host-parasite systems, such information probably exists, so valuable inferences can already be made. Second, the potential importance of any interactions can be revealed by conducting experiments under a range of temperatures, exploring temperature variation and realistic upper and lower extremes, as well as constant temperatures. Finally, a recent study exploring the effects of assay conditions in life-history experiments with Drosophila has revealed that conclusions about responses to selection depend upon the environment in which the assay was performed [68]. Studies of other model communities indicate that costs of resistance (i.e. tradeoffs with other traits, such as competitive ability) might also vary depending on the environment [69]. We suggest, therefore, that in studying coevolution of hosts and parasites and other correlated responses, it might be more valuable to derive measures of life-history traits from the response of the genotype across the relevant environmental range (i.e. the area under the reaction norm), rather than use a snapshot measure estimated under just one set of conditions.

\section{Acknowledgements}

We are grateful to three anonymous reviewers for helpful comments on the article. The paper forms a part contribution to the EU-funded 'Environmentally Sustainable Locust Control Programme (ESLOCO - QLK5-CT1999-01118)' and the project 'Development of biologically based strategies for sustainable control of red locust in Central and Southern Africa' funded by United Kingdom Department for International Development (DFID) for the benefit of developing countries (R7818 Crop Protection Research Programme). The views expressed are not necessarily those of DFID.

\section{References}

1 Lacey, L.A. et al. (2001) Insect pathogens as biological control agents: do they have a future? Biol. Contr. 21, 230-248

2 Blanford, S. and Thomas, M.B. (1999) Host thermal biology: the key to understanding insect-pathogen interactions and microbial pest control? Agric. Forest Entomol. 1, 195-202

3 Blanford, S. and Thomas, M.B. (1999) Role of thermal biology in disease dynamics. Aspects Appl. Biol. 53, 73-82

4 Inglis, D.G. et al. (1996) Effects of temperature and thermoregulation on mycosis by Beauveria bassiana in grasshoppers. Biol. Contr. 7, 131-139

5 Inglis, D.G. et al. (1997) Effects of temperature and sunlight on mycosis (Beauveria bassiana) (Hyphomycetes: Sympodulosporae) of grasshoppers under field conditions. Environ. Entomol. 26, 400-409

6 Arthurs, S. and Thomas, M.B. (2000) Effects of a mycoinsecticide on feeding and fecundity of the brown locust, Locustana pardalina. Biocontr. Sci. Technol. 10, 321-329

7 Blanford, S. and Thomas, M.B. (2000) Thermoregulation by two acridid species: effects of habitat and season on thermal behaviour and the potential impact on biocontrol with pathogens. Environ. Entomol. $29,1060-1069$

8 Lomer, C.J. et al. (2001) Biological control of locusts and grasshoppers. Annu. Rev. Entomol. 46, 667-702

9 Chapman, R.F. and Page, W.W. (1979) Factors affecting the mortality of the grasshopper, Zonocerus variegatus, in Southern Nigeria. J. Anim. Ecol. 48, 271-288

10 Blanford, S. et al. (2000) Thermal ecology of Zonocerus variegatus and its effect on biocontrol using pathogens. Agric. Forest Entomol. 2, 3-10

11 Carruthers, R.I. et al. (1992) Influence of thermal ecology on the mycosis of a rangeland grasshopper. Ecology 73, 190-204

12 Watson, D.W. et al. (1993) Behavioural fever response of Musca domestica (Diptera: Muscidae) to infection by Entomophthora muscae (Zygomycetes: Entomophthorales). J. Invert. Pathol. 61, 10-16

13 Hajek, A.E. et al. (1993) Modelling the dynamics of E. maimaiga (Zygomycetes: Entomophthorales) epizootics in gypsy moth (Lepidoptera: Lymantriidae) populations. Environ. Entomol. 22, 1172-1187
14 McGuire, M.R. et al. (1987) Effect of temperature in the distribution and success of introduction of an Empoasca fabae (Homoptera: Cicadellidae) isolate of Erynia radicans (Zygomycetes: Entomophthoraceae). J. Invertebr. Pathol. 50, 291-301

15 Blanford, S. et al. (2003) Temperature checks the Red Queen? Resistance and virulence in a variable environment. Ecol. Lett. 6, 2-5

16 Stacey, D.A. et al. Genotype and temperature influence pea aphid resistance to a fungal entomopathogen. Physiol. Entomol. (in press)

17 Yadava, R.L. (1970) Studien über den einfluß von temperatur und relativer luftfeuchtigkeit auf die entwicklung der kernpolyedrose der Nonne (Lymantria monacha L.) und des Schwammspinners (L. dispar L.). Z. Agnew Entomol. 65, 167-174

18 Kobayashi, M. et al. (1981) Effect of high temperature on the development of nuclear polyhedrosis virus in the silkworm, Bombyx mori. J. Invertebr. Pathol. 38, 386-394

19 Mohamed, M.A. et al. (1985) Temperature and crowding effects on virus manifestation in Neodiprion sertifer (Hymenoptera: Diprionidae) larvae. Great Lakes Entomol. 18, 115-118

20 Adamo, S.A. (1998) The specificity of behavioural fever in the cricket Acheta domesticus. J. Parasitol. 84, 529-533

21 Olsen, L.E. and Hoy, M.A. (2002) Heat curing Metaseilus occidentalis (Nesbit) (Acari, Phytoseiidae) of a fitness-reducing mircosporidium. J. Invertebr. Pathol. 79, 173-178

22 Frid, L. and Myers, J.H. (2002) Thermal ecology of western tent caterpillars, Malacosoma californnicum pluviale, and infection by nucleopolyhedrovirus. Ecol. Entomol. 27, 665-673

23 Menti, H. et al. (2000) Infectivity of populations of the entomoptahogenic nematodes Steinernema feltiae and Heterorhabditis megidis in relation to temperature, age and lipid content. Nematology 2, 515-521

24 Kraaijeveld, A.R. and Godfray, H.C.J. (1997) Trade-off between parasitoid resistance and larval competitive ability in Drosophila melanogaster. Nature 389, 278-280

25 Fellowes, M.D.E. et al. (1999) Cross resistance following artificial selection for increased host defence against parasitoids in Drosophila melanogaster. Evolution 53, 966-972

26 Blumberg, D. (1991) Seasonal variations in the encapsulation of eggs of the encyrtid parasitoid, Metaphycus stanleyi, by the pyriform scale, Protopulvinaria pyriformis. Entomol. Exp. Appl. 58, 231-237

27 Geden, C.J. (1997) Development models for the filth fly parasitoids Spalangia gemina, S. cameroni, and Muscidifurax raptor (Hymenoptera: Pteromalidae) under constant and variable temperatures. Biol. Contr. 9, 185-192

28 Sigsgaard, L. (2000) The temperature-dependent duration of development and parasitism of three cereal aphid parasitoids, Aphidius ervi, A. rhopalosiphi, and Praon volucre. Entomol. Exp. Appl. 95, 173-184

29 Liu, S.S. et al. (2001) The biology of Daidromus collaris (Hymenoptera: Ichneumonidae), a pupal parasitoid of Plutella xylostella (Lepidoptera: Plutellidae), and its interaction with Oomyzus sokolowskii (Hymenoptera: Eulophidae). Bull. Entomol. Res. 91, 461-469

30 Werren, J.H. (1997) Biology of Wolbachia. Annu. Rev. Entomol. 42, 587-609

31 Douglas, A.E. (1998) Nutritional interactions in insect-microbial symbioses: aphids and their symbiotic bacteria Buchnera. Annu. Rev. Entomol. 43, 17-37

32 Aksoy, S. et al. (2001) Prospects for control of African trypanosomoiasis by tsetse vector manipulation. Trends Parasitol. 17, 29-35

33 Johanowicz, D.L. and Hoy, M.A. (1998) Experimental induction and termination of non-reciprocal reproductive incompatibilities in a parahaploid mite. Entomol. Exp. Appl. 87, 51-58

34 Pintureau, B. and Bolland, P. (2001) A Trichogramma species showing a better adaptation to high temperatures than its symbionts. Biocontr. Sci. Technol. 11, 13-20

35 Montllor, C.B. et al. (2002) Facultative bacterial endomsymbionts benefit pea aphids Acyrthosiphon pisum under heat stress. Ecol. Entomol. 27, 189-195

36 Fiahlo, R.F. and Schall, J.J. (1995) Thermal ecology of a malarial parasite and its insect vector: consequences for the parasite's transmission success. J. Anim. Ecol. 64, 553-562

37 Craig, M.H. et al. (1999) A climate-based distribution model of malaria transmission in sub-Saharan Africa. Parasitol. Today 15, 105-111

38 Mellor, P.S. (2000) Replication of arboviruses in insect vectors. J. Comp. Pathol. 123, 231-247

39 Elliot, S.L. et al. (2002) Host-pathogen interactions in a varying 
environment: temperature, behavioural fever and fitness. Proc. R. Soc. Lond. Ser. B 269, 1599-1607

40 Chappell, M.A. and Whitman, D.A. (1990) Grasshopper thermoregulation. In Biology of Grasshoppers (Chapman, R.F. and Joern, A., eds) pp. 143-172, Wiley Interscience

41 Blanford, S. et al. (1998) Behavioural fever in a population of the Sengalese grasshopper, Oedaleus senegalensis, and its implications for biological control using pathogens. Ecol. Entomol. 23, 9-14

42 Starks, P.T. et al. (2000) Fever in honeybee colonies. Naturwissenshaften $87,229-231$

43 Ouedraogo, R.M. et al. Inhibition of fungal growth in thermoregulating locusts, Locusta migratoria, infected by the fungus Metarhizium anisopliae var. acridum. J. Invertebr. Pathol. (in press)

44 McClain, E. et al. (1988) Behavioural fever in a Namib desert tenebrionid beetle, Onymacris plana. J. Insect Physiol. 34, 279-284

45 Mitchell, D. et al. (1990) Fever in Namib and other ectotherms. In Namib Ecology: 25 Years of Namib Research In Transvaal Museum Monograph No 7 (Selly, M.K. et al., eds), pp. 179-192, Transvaal Museum

46 Maitland, D.P. (1994) A parasitic fungus infecting yellow dungflies manipulates host perching behaviour. Proc. R. Soc. Lond. Ser. B 258, 187-193

47 Karban, R. (1988) Caterpillar basking behaviour and nonlethal parasitism by tachinid flies. J. Insect Behav. 11, 714-723

48 Kluger, M.J. et al. (1998) Role of fever in disease. Mol. Mech. Fever 856, 224-233

49 Vilmos, P. and Kurucz, E. (1988) Insect immunity: evolutionary roots of mammalian innate immune system. Immunol. Lett. 62, 59-66

50 Franc, N.C. and White, K. (2000) Innate recognition systems in insect immunity: new approaches in Drosophila. Microbes Infect. 2, 243-250

51 Aderem, A. and Ulevitch, R.J. (2000) Toll-like receptors in the induction of the innate immune response. Nature 406, 782-787

52 Dimopoulos, G. et al. (2001) Innate immune defence against malaria infection in mosquito. Curr. Opin. Immunol. 13, 79-88

53 Kelly, P.M. and Entwistle, P.F. (1988) In vivo mass production in the cabbage moth (Mamestra brassicae) of a heterologous (Panolis) and homologous (Mamestra) nuclear polyhedrosis virus. J. Virol. Methods 19, 249-256

54 Wilson, K. et al. (2001) Melanism and disease resistance in insects. Ecol. Lett. 4, 637-649

55 Wilson, K. et al. (2002) Coping with crowds: density-dependent disease resistance in desert locusts. Proc. Natl. Acad. Sci. U. S. A. 99, 5471-5475

56 Bonsall, M. (2002) Evolutionary and ecological aspects of disease and parasitism. Trends Ecol. Evol. 17, 401-403

57 Yourth, C.P. et al. (2002) Immune expression in a damselfly is related to time of season, not to fluctuating asymmetry or host size. Ecol. Entomol. 27, 123-128

58 Lance, D.R. et al. (1987) Microhabitat and temperature effects explain accelerated development during outbreaks of the gypsy moth (Lepidoptera: Lymantriidae). Environ. Entomol 16, 202-205

59 Gunn, A. (1998) The determination of larval phase coloration in the African armyworm, Spodoptera exempta, and its consequences for thermoregulation and protection from UV light. Entomol. Exp. Appl. $86,125-133$

60 Kraaijeveld, A.R. et al. (1998) The coevolution of host resistance and parasitoid virulence. Parasitology 116, S29-S45

61 Ebert, D. et al. (1998) Within- and between-population variation for resistance of Daphnia magna to the bacterial endoparasite Pasteuria ramosa. Proc. R. Soc. Lond. Ser. B 265, 2127-2134

62 Henter, H.J. and Via, S. (1995) The potential for coevolution in a hostparasitoid system. I. Genetic variation within an aphid population in susceptibility to a parasitic wasp. Evolution 49, 427-438

63 Ferrari, J. et al. (2001) Clonal variation and covariation in aphid resistance to parasitoids and a pathogen. Evolution 55, 1805-1814

64 Little, T.J. and Ebert, D. (2001) Temporal patterns of genetic variation for resistance and infectivity in a Daphnia-microparasite system. Evolution 55, 1146-1152

65 Eady, S.J. et al. (1996) Resistance to nematode parasites in Merino sheep: sources of genetic variation. Aust. J. Agric. Res. 47, 895-915

66 Singh, N. et al. (1997) Infectious diseases and immunity: special reference to the major histocompatibility complex. Emerg. Infect. Dis. $3,41-49$

67 Ferguson, H.M. and Read, A.F. (2002) Genetic and environmental determinants of malaria parasite virulence in mosquitoes. Proc. R. Soc. Lond. Ser. B 269, 1217-1224

68 Ackermann, M. et al. (2001) Effects of assay conditions in the life history experiments with Drosophila melanogaster. J. Evol. Biol. 14, 199-209

69 Bohannan, B.J.M. and Lenski, R.E. (2000) Linking genetic change go community evolution: insights from studies of bacteria and bacteriophage. Ecol. Lett. 3, 362-377

70 Huey, R.B. and Kingsolver, J.G. (1989) Evolution of thermal sensitivity of ectotherm performance. Trends Ecol. Evol. 4, 131-135

71 Huey, R.B. and Hertz, P.E. (1984) Is a jack-of-all temperatures a master of none? Evolution 38, 441-444

72 Roy, M. et al. (2000) Relationship between temperature and developmental rate of Stethorus punctillum (Coleoptera: Coccinellidae) and its prey Tetranychus mcdanieli (Acarina: Tetranychidae). Environ. Entomol. 31, 177-187

73 Hertz, P.E. et al. (1983) Homage to Santa Anita: thermal sensitivity of sprint speed in Agamid lizards. Evolution 37, 1075-1084

74 Bennet, A.F. et al. (1992) Evolutionary adaptation to temperature. I. Fitness responses of Escherichia coli to changes in its thermal environment. Evolution 46, 16-30

75 Malakar, R. (1999) Within-host interactions of Lymatria dispar (Lepidoptera: Lymantridae) nucleopolyhedrosis virus and Entomophaga maimaiga (Zygomycetes: Entomophthorales). J. Invertebr. Pathol. 73, 91-100

76 Johnson, D.W. et al. (1982) A temperature-dependent development model for a nucleopolyhedrosis virus of the velvetbean caterpillar Anticarsia gemmatalis (Lepidoptera: Noctuidae). J. Invertebr. Pathol. 40, 292-298

77 Heinrich, B. (1977) Why have some animals evolved to regulate a high temperature? Am. Nat. 111, 623-640

78 Wellington et al. (1999) Weather and insects. In Ecological Entomology (Gutierrez, A. et al., eds), pp. 313-353, John Wiley \& Sons

79 Heinrich, B. (1993) The Hot blooded Insects, John Wiley \& Sons

80 Kemp, W.P. (1986) Thermoregulation in three rangeland grasshoppers. Can. Entomol. 118, 335-343

81 Heath, J.E. (1964) Reptilian thermoregulation: evaluation of field studies. Science 146, 784-785

82 Huey, R.B. (1974) Behavioural thermoregulation in lizards: importance of associated costs. Science 184, 1001-1003

83 Dreisig, H. (1984) Control of body temperature by shuttling ectotherms. J. Therm. Biol. 9, 229-233

\section{Do you want to reproduce material from a Trends journal?}

This publication and the individual contributions within it are protected by the copyright of Elsevier Science. Except as outlined in the terms and conditions (see p. ii), no part of any Trends journal can be reproduced, either in print or electronic form, without written permission from Elsevier Science. Please address any permission requests to:

Rights and Permissions,

Elsevier Science Ltd,

PO Box 800, Oxford, UK OX5 1DX. 